\title{
Study on the Construction Mode of Water Ecological Civilization in Coastal Cities_-Taking Shenzhen as an Example
}

\author{
Hanxiu Fu ${ }^{1,2}$, Yong Liu ${ }^{1}$, Yuanfang $\mathrm{Chen}^{2}$, Jian $\mathrm{Hu}^{3}$, Ying Zhang ${ }^{4}$, Qingfang $\mathrm{Hu}^{1}$ \\ ${ }^{1}$ State Key Laboratory of Hydrology-Water Resources and Hydraulic Engineering, Nanjing Hydraulic Research Institute, Nanjing city, \\ 210029, China \\ ${ }^{2}$ College of Hydrology and Water Resources, Hohai University, Nanjing city, 210098, China \\ ${ }^{3}$ Key Laboratory of Water Cycle and Related Land Surface Processes, Institute of Geographic Sciences and Natural Resources Research, \\ Chinese Academy of Sciences, Beijing city, 100101, China \\ ${ }^{4}$ Hydraulic Engineering Planning Bureau of Jiangsu Province, Nanjing city, 210029, China
}

\begin{abstract}
Based on the present situation of water ecological civilization construction in Shenzhen, the paper summarizes the path of water ecological civilization construction with Shenzhen characteristics. That is to say, the construction is around the development vision of "river and sea are calm and peaceful, green mountains and clear water, modern livable, beautiful Pengcheng", to create the eight major systems of water safety, water environment, water ecology, water conservation, water management, water landscape, water economy and water culture according to local conditions on the basis of the spatial layout of "nine basins and four sections, three bays and two belts, five-point and dual-core". This construction mode provides an important reference for promoting the governance of Shenzhen water problems under the guidance of the concept of ecological civilization and provides a model reference for the construction of water ecological civilization in coastal cities $^{[1,2,6]}$.
\end{abstract}

\section{Progress on the construction of water ecological civilization city}

Since 2013, the Ministry of Water Resources has selected 105 cities (counties and districts) as pilots to carry out water ecological civilization construction work. The national water ecological civilization construction has been piloted first and gradually promoted in a pointto-face manner ${ }^{[4]}$. Pilot cities explore the construction models and experiences under different development levels, different water resources conditions, and different water ecological conditions. These pilot cities will provide guidance and demonstration for the comprehensive creation of water ecological civilization cities in the whole country. It is expected that the acceptance of 105 pilot projects for the construction of water ecological civilization cities will be completed in two batches by the end of 2018 .

\section{Overview of the study region}

Shenzhen is located on the east bank of the Pearl River Delta, east of Daya Bay and Dapeng Bay, west of the Pearl River Estuary and Lintin, separated from Hong Kong by water ${ }^{[3]}$ (Figure 1). Shenzhen is located on the eastern coast of the Pearl River Delta, with a humid climate, good water and water ecological background conditions, and solid foundations for water engineering and water resources management. In recent years,
Shenzhen's water construction has achieved remarkable results. However, Shenzhen is a small space city, a small resource city and a small environmental capacity city with a land area of less than $2000 \mathrm{~km}^{2}$. Since the establishment of the city, the rapid urbanization, industrialization and high intensity of human activities have greatly exceeded the limits of water resources and water environment carrying capacity, and the water ecosystem function has been seriously damaged ${ }^{[3]}$. It is urgent to carry out the construction of water ecological civilization city in Shenzhen.

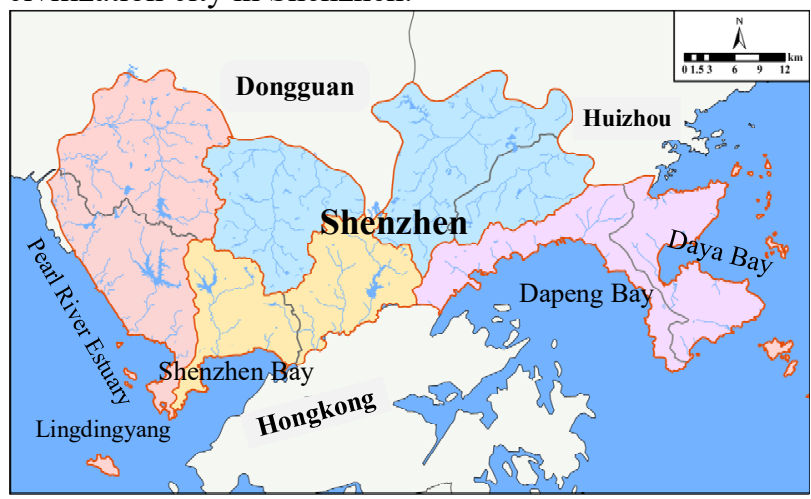

Figure 1. location map of Shenzhen.

\section{Spatial layout of water ecological civilization construction with Shenzhen characteristics}

a Corresponding author: Yong Liu: yongliu@nhri.cn 
Under the guidance of the concept of ecological civilization, according to the idea of "basing on the life community of mountain, river, forest, field and lake, coordinating all the elements of natural ecology", according to the topography and water system vein in Shenzhen, and considering the urban development pattern and ecological function zoning, Shenzhen will build the spatial layout of water ecological civilization construction of "nine basins four sections, three bays two belts, five-point dual-core"(Figure 2), the construction of water ecological civilization will be closely linked with urban development and ecological environment protection.

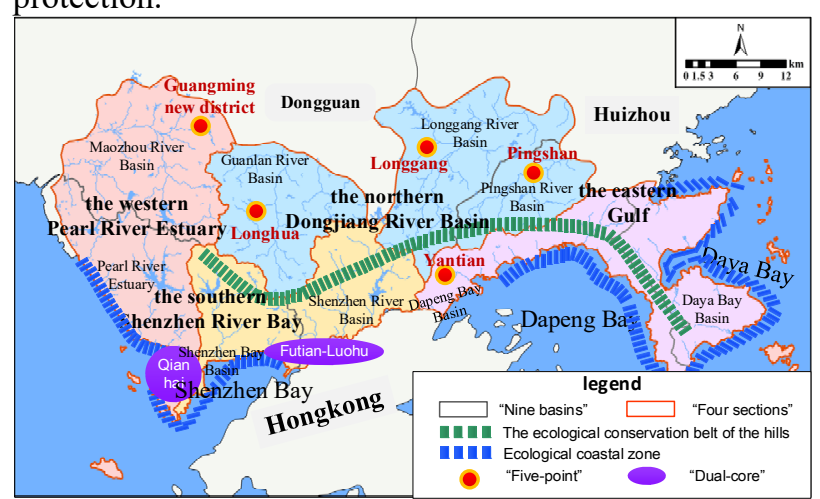

Figure 2. sketch map of spatial layout of Shenzhen's water ecological civilization city construction.

\subsection{Nine basins and four sections}

Shenzhen is divided into nine basins, which are divided into four parts of the East, South, West and South. Among them, the nine basins are Maozhou River Basin, Pearl River Estuary system, Shenzhen Bay Basin, Shenzhen River Basin, Guanlan River Basin, Longgang River Basin, Pingshan River Basin, Dapeng Bay Basin and Daya Bay Basin. The four regions are the western Pearl River Estuary, the southern Shenzhen River Bay, the northern Dongjiang River Basin and the eastern Gulf.

The main stream of the nine basins and the main tributaries are the main water ecological corridors in Shenzhen. The focus is on strengthening the control of the blue line, coordinating flood control, water resource allocation, water pollution control, water ecological restoration and water landscape construction, and accelerating comprehensive remediation. Due to the different conditions in the four major districts, the construction of water ecological civilization needs to be promoted by classification.

The Shenzhen River Bay area is an international center and a world-class coastal area. The focus of this area is to implement comprehensive regulation of the Shenzhen River and its main tributaries, to improve the supporting facilities for water pollution control, to comprehensively improve the quality of the water environment, and to create high-quality urban water environment and water landscape.

The Pearl River Estuary area is a demonstration area for comprehensive watershed management. The emphasis of this area is to complete the construction of the national sponge city demonstration area, to strengthen the connection of the large airport and other water systems, to promote the overall improvement of flood control and water-logging control, water environment treatment, and water supply support capacity.

The Dongjiang River Basin is a key area for crossborder river management. The focus is on developing green low-carbon and high-end manufacturing industries, vigorously improving water infrastructure, and accelerating the comprehensive improvement of transboundary rivers such as Longgang River, Pingshan River and Guanlan River to ensure that the water quality of the cross-border river junction reaches the standard.

The Eastern Bay region is a green ecological protection area, which focuses on improving the basic pipe network facilities, strengthening the protection of water resources and water ecosystems, coordinating the ecological protection, open coastal space and urban development with the concept of low-impact development, and building ecological paradise and world-class coastal ecological tourism resorts.

\subsection{Three bays and two belts}

From west to east, the three bays are followed by Shenzhen Bay, Dapeng Bay and Daya Bay. The two zones refer to the coastal zone along the coast and the ecological conservation belt of the central hills. The focus of the three bays is to strengthen the coordination of land and sea, to protect and restore coastal wetland ecosystems, to improve the offshore water quality environment, and to strengthen the management and control of development activities. The emphasis of the two zones is to strengthen vegetation protection, water and soil conservation, to build clean small watersheds, and to strengthen the use of rain and flood and the protection of the water quality of drinking water sources.

\subsection{Five-point and dual-core}

The five points are the five urban sub-centers of Guangming new district, Longgang, Pingshan, Longhua and Yantian in Shenzhen. The double cores are FutianLuohu and Qianhai two urban centers. The five-point and dual-core is the core area of Shenzhen's water ecological civilization construction. The key point is to coordinate resources such as mountains, water, parks, green spaces and humanities, to speed up the construction of green low-carbon production and consumption patterns, to strengthen the comprehensive management of water environment, to vigorously build sponge city and water-saving city, to strengthen the whole process of water management, to eliminate the black stink of the water body and the city water-logging, and to shape the urban water landscape and ecological space with cultural quality to promote the harmonious coexistence between man and nature.

\section{Main measures for the construction of water ecological civilization cities}


Starting from the overall goal and spatial layout of Shenzhen's water ecological civilization construction, we will take into account the relevant work and requirements of all regions and departments of the city, and comprehensively promote the construction of the eight major systems of Shenzhen's water ecological civilization cities.

\subsection{Build a complete and reliable water safety system}

The construction is built according to the idea of "two rivers parallel development, multiple water sources complementation". The construction is to optimize the layout of water resources projects in Shenzhen, to actively expand overseas high-quality water sources, to tap the potential of local water resources utilization, to focus on the water quality protection of the water source, to improve water transmission and distribution projects and networks, and to improve emergency reserve capacity. In the end, a water resource utilization allocation system that is flexible, safe and reliable will be built, the whole process of water supply security from source to the end will be realized, and the basic support and support ability of water resources for Shenzhen's urban development will be comprehensively enhanced.

\subsection{Establish a clean and high quality water environment system}

The construction of this system adopt the model of clearing source, reducing capacity, process management and land-water coordination, focus on sensitive waters such as river black and odorous water bodies and coastal waters, promote the comprehensive management of water environment in Shenzhen, improve the environmental quality of inland and offshore waters, and create clean and high quality water environment system.

\subsection{Form a healthy and benign water ecosystem}

On the one hand, water ecosystem construction adhere to the policy of "protection first and moderate restoration", implement the strategy of "coordinate sea and land, optimize the environment, and coordinated development ", build a healthy and benign, complete and diverse water ecosystem. On the other, the construction need firmly establish the concept of mountain, water, field, forests and lake life community, adhere to the principle of "prevention first, protection priority, and moderate restoration", strengthen the city's ecological space and urban development and construction management, optimize the spatial layout of urban development and industrial development, implement the management of ecological red line and river-lake blue line, strengthen the protection of water ecological sensitive areas and biodiversity, form a threedimensional soil and water conservation network, promote the natural and artificial restoration of land and sea water ecology, and strive to build a water ecosystem with reasonable layout, versatility, health and stability.

\subsection{Achieve efficient and intensive water conservation systems}

The key to the construction of water conservation system lies in strengthening the rigid restriction of water consumption and water quota, promoting the transformation and upgrading of economic structure and industrial layout adjustment, and controlling and reducing water resources consumption from the source. First, we should accelerate the technical reform of industrial water-saving, promote the adoption of new water-saving technologies, new equipment, strengthen the recycling water, and increase the reuse rate of industrial water. Second, we need optimize the regional water supply system, strengthen water supply network reconstruction and operation maintenance, reduce the leakage rate of the water supply pipe network. Third, we should actively promote the use of unconventional water resources, expand the use of rainwater, reuse water and seawater utilization, build a reclaimed water utilization pipe network system and a quality water supply system, and expand the seawater desalination demonstration project according to local conditions. Fourth, we need conduct water efficiency leaders to lead the action, give full play to the demonstration of various water-saving carriers, strengthen the scale effect of water-saving carriers, and improve the coverage of water-saving carriers such as water-saving enterprises and watersaving schools. Last, we need strengthen the management of planned water use and water saving "three simultaneous" management, improve the watersaving supporting laws and regulations, and consolidate the long-term mechanism of water saving.

\subsection{Create a rich and pleasant water landscape system}

The main construction path of the water landscape system is to rely on the landscape and urban pattern of Shenzhen, to rely on reservoirs, wetlands, lakes and ponds, rivers, offshore waters and other types of waters (water bodies), to combine modern engineering aesthetics with landscape art, to build eco-friendly, functional composite, rich and pleasant water landscapes which show the natural features and cultural customs of Shenzhen. The specific measures have the following five aspects. First, we should optimize the landscape of water projects and build a group of distinctive wading scenic spots, forest parks and wetland parks. Second, we can combine the planning of forest parks and water conservancy scenic areas to gradually open small nonwater supply reservoirs as a leisure space for citizens. Third, we need establish high-standard demonstration wetland parks, promote Shenzhen Bay Park and other provincial wetland parks, and speed up the construction or optimization of artificial wetlands such as Qinghu. Fourth, we should integrate the comprehensive improvement of the river basin with the landscape garden and municipal traffic construction, rationally create the waterfront landscape, highlight the organic protection of the natural ecological landscape and the authenticity of the local culture, create an urban 
ecological leisure belt and cultural display space for clear water and green shore, and optimize human's settlement environment. Last, we should make full use of the characteristics of the east and west coasts of Shenzhen to create a natural ecological and cultural leisure space for coastal cities, and build a number of coastal water landscape such as the former seawater corridor and the Shenzhen Bay coastal ecological corridor.

\subsection{Develop a green and innovative water economy system}

The construction path of the water economic system is to vigorously cultivate the development of green waterrelated industries, improve the degree of marketization of water affairs, optimize the economic input of water ecological civilization construction, improve the implementation of ecological environmental damage compensation and economic compensation mechanisms, and form a green, pluralistic and innovative water economy development form. Specific measures should be promoted from the following four aspects. First, we need expand the cooperation between government and social capital, build a water environment governance and water ecological protection market system, attract social capital to participate in the construction of Shenzhen water ecological civilization, and strengthen the economic guarantee for the development of water affairs. Next, we should cultivate a new type of aquatic industry, actively promote the development of low-carbon and recycling industries, develop a new high-tech water environmental protection and information industry, and create a highland and industrial business card for the water control industry in Shenzhen. And then, we need coordinate the comprehensive management of river basins, give impetus to the renovation and industrial upgrading of old areas, promote the development of green low-carbon industries such as wading health and leisure, ecotourism, cultural creativity, drive the development of characteristic business districts, characteristic neighborhoods, creative workshops and innovative parks. Finally, we can give full play to the role of market allocation and economic leverage, promote the reform of tap water and raw water prices in Shenzhen, optimize the ladder water price, innovate the sewage treatment payment model, improve the environmental pollution compulsory liability insurance system, steadily promote the paid use and trading of emission rights, implement the compensation system for ecological environmental damage and improve the ecological compensation mechanism in Shenzhen.

\subsection{Establish a strict and advanced water management system}

There are five contents in the construction of water management system. First, we need deepen the most stringent water resources management system, improve supporting policies. Second, we should comprehensively implement the River Chief System, establish a system of graded River Chief in Shenzhen, and promote the "one river, one policy" management model of "the responsibility of the river chief and the departmental governance". Third, we need further straighten out the water affairs management mechanism system. Fourth, we should perfect the monitoring network system, improve the level of informatization, and build a smart water affairs system consisting of "one net, one center, one map, one platform". Fifth, we shoulf perfect the water affairs standard system, strengthen water affairs technology innovation and the construction of talent team.

\subsection{Cultivate an inclusive and open water culture system}

The goal of the construction of the water culture system is to enhance the public's awareness of the construction of the water ecological civilization city, strengthen public participation and create a good social atmosphere. There are five specific contents. First, we should protect Shenzhen's wading cultural heritage, inherit the excellent traditional water culture. Second, we need innovate and develop modern water culture, and carry out extensive propaganda of ecological civilization. Third, we should speed up the construction of various water culture propaganda and education carriers. Fourth, we need cultivate a water culture system that is inclusive and open, integrate the historical and cultural background of Lingnan and the urban temperament of Shenzhen, and conform to the trend of modern ecological civilization. Finally, we should guide the public to actively participate in the construction of water ecological civilization, raise the awareness of water ecological civilization to the height of ecological awareness and development consciousness ${ }^{[5]}$.

\section{Future prospects}

Through the construction of water ecological civilization city in Shenzhen, the concept of ecological civilization is deeply embedded in all aspects of water resources development, utilization, treatment, allocation, conservation, protection and restoration, and all aspects of water planning, construction and management ${ }^{[1,7]}$. After the completion of the construction, not only can the Shenzhen water system maintain a virtuous circle, provide sustainable support and guarantee for economic and social development, but also realize the coordinated development of water resources utilization and protection and economic and social, and form a stable and harmonious relationship between urban people and water. Eventually, the water ecological civilization city vision of "river and sea are calm and peaceful, green mountains and clear water, modern livable, beautiful Pengcheng" can be fully displayed.

\section{Acknowledgements}

This research was financially supported by the National Key Research and Development Program of China (No. 
2016YFC0401502,2016YFC0400910,

2016YFC0401508), the National Natural Science Foundation of China (No. 51609140, 51809252, 51509157), Jiangsu Provincial Water Resources Technology Project(2017037).

\section{References}

1. Q.F. Hu, J.J. Huo, L.J. Li, Index system of water ecological civilization city: perspectives and suggestions[J], Journal of Yangtze River Scientific Research Institute, 35(8), 22-26(2018)

2. Q.F. Hu, Y.T. Wang, L.J. Li, Preliminary comparison between water-ecological civilization city and sponge city[J], Water Resources Protection, 33(5), 13-18(2017)

3. C. Luo, Y. Liu, X.Q. Zhu, Tempo-spatial changes of precipitation of Shenzhen in last 57 years[J], Hydroscience and Engineering , (3), 24-31 (2018)

4. W.Y. Zhao, J.X. Yang, J.R. Liu, Progress and thinking on the construction of water ecological civilization[J], China Population, Resources and Environment, 24, 160-163(2014)

5. Q.T. Zuo, Discussions on key issues of water ecological civilization construction[J], China Water Resources, (2013)

6. M.K. Xu, X. Chen, H.F. Wang, Evaluation of water eco-civilization construction in Qingdao[J], Journal of Water Resources \& Water Engineering, 28(6), 109-114(2017)

7. J.Y. Li, Considerations of initiating water ecological civilization in the new age[J], China Water Resources, 3-6(2018) 